\title{
Economic analysis of water reuse in Spain
}

\author{
J. M. Moreno ${ }^{1,2}$ \& L. D. Chabalina ${ }^{2}$ \\ ${ }^{1}$ Department of Applied Economic Analysis, University of Alicante, Spain \\ ${ }^{2}$ Water and Environmental Science Institute, University of Alicante, Spain
}

\begin{abstract}
The remarkable development of reuse of water in Spain has taken place not only because of the necessity to extend water supplies, but also due to the requirements to improve the management in water treatment. Water supply consumption has increased, along with the increase of population that has taken place in numerous urban zones. As a result, traditional supplying sources are insufficient to satisfy the demand, which is in permanent expansion. This paper will analyze from an economical point of view, the effects of the Directive $91 / 271 /$ EEC in Spain, as well as the new rule that appears in the Order in Council of December 8, 2007 in which the legal regime of treated water reuse is established. Furthermore, costs of reused and recycled water by means of different treatment systems will be discussed, as well as the environmental costs associated to them.
\end{abstract}

Keywords: treated water reuse, economic analysis, environmental and economic costs, legal regime.

\section{Introduction}

The increase reached by water supplies, as well as the increase of population which took place in numerous urban areas, have caused that the traditional supplying sources are insufficient to satisfy the demand, which is in permanent expansion. Environmental limitations and plurianual droughts have led numerous towns to use treated water as an additional water source to take advantage of it, in case drinkable water quality was not necessary. At the same time, sanitary and environmental requirements of continental and marine water quality are rising, in addition to the requirements of location and treatment levels which are more and more strict. For that reason, recycled water has been turned into an alternative 
source of supplying, economic and assured from the sanitary and environmental point of view.

The modification of the National Water Plan, made from the Order in Council $2 / 2004$, has supposed an important change in the hydraulic policy. That has been achieved thanks to the development of activities as desalination and wastewater reuse in basins with lack of water in different fields of water planning. This paper will be focused on water recycling.

Directive 91/271/CEE, in its article 12 establishes: "1. Treated wastewater will be reused when it proceeds. The evacuation methods will reduce up to the minimum adverse effects on the environment". In Spain, the National Plan of Sanitation and Wastewater Treatment also has established, the promotion of wastewater reuse, as an important management point in the hydraulic domain (published in the Resolution of April 28 ${ }^{\text {th }}$, 1995, of the Secretary of State for the Environment, by which is stated in the Cabinet Meeting of February $17^{\text {th }}, 1995$, of which the National Plan of Sanitation and Wastewater Treatment was approved, BOE $n^{\circ} .113$ of May $12^{\text {th }}, 1995$.).

The reuse of treated wastewater must not be considered isolated and exclusively in function of the benefit that it could produce on users. Recycled wastewaters must be considered as an unconventional resource, which its management must be included in an integral water resources planning, taking into account economic, social and environmental aspects. Reuse can raise the availability of water resources. As a result, the improvement of effluents quality is the key of the use and water management. This way, recycled water can replace uses that do not need a high quality, avoiding using volumes of better quality for other more demanding uses.

\section{Discussion}

\subsection{State of treatment and water reuse in Spain}

From the legal point of view, the promotion of building sites associated to wastewater reuse can be carried out by the state administration through the basin organizations and by the state societies if buildings are considered of general interest, in accordance with the autonomous regions if it is also considered as an autonomic interest. Finally, it is possible that users' regions could take part in this type of action in its condition of public administrations of corporative nature, especially when the actions are related to irrigation.

According to the Ministry of Environment (MIMAM), wastewater treatment in Spain in 2004 covered 2.700 city centres, treating a total load of 70.130 .000 equivalent inhabitants (EI). Although the Directive 91/271/CEE was fulfilled, it is not clearly aimed to wastewater reuse, therefore effluents can not be used for many potential uses.

Figure 2 shows the fulfilment degree of the objectives of yield and quality established in the Directive.

With regard to the state of wastewater reuse in Spain, the maximum volume is limited by the amount of urban treated water, by the geographic location with 
respect to the use of these facilities, by the demand, by the resource acceptance and by its economic and environmental viability. In El Libro Blanco en España [1], it was expected that the maximum volume of treated effluents will reach $3,500 \mathrm{hm}^{3} /$ year, once finalized the National Plan of Sanitation and Treatment in accordance with the Directive 91/271/CEE. Approximately 1,200 $\mathrm{hm}^{3} /$ year of that water could be reused. In $2005,2,400 \mathrm{hm}^{3}$ of wastewater was treated, of which $17 \%$ was reused [2]. Although the percentage of reused water with respect to the total of available resources is small $(2,67 \%)$, this one becomes strategic and even essential in some zones of Spain, mainly in those that have a structural deficit. The majority of the projects already done or in study phase, have an agricultural purpose, showing an increasing trend to reuse water with environmental aims.
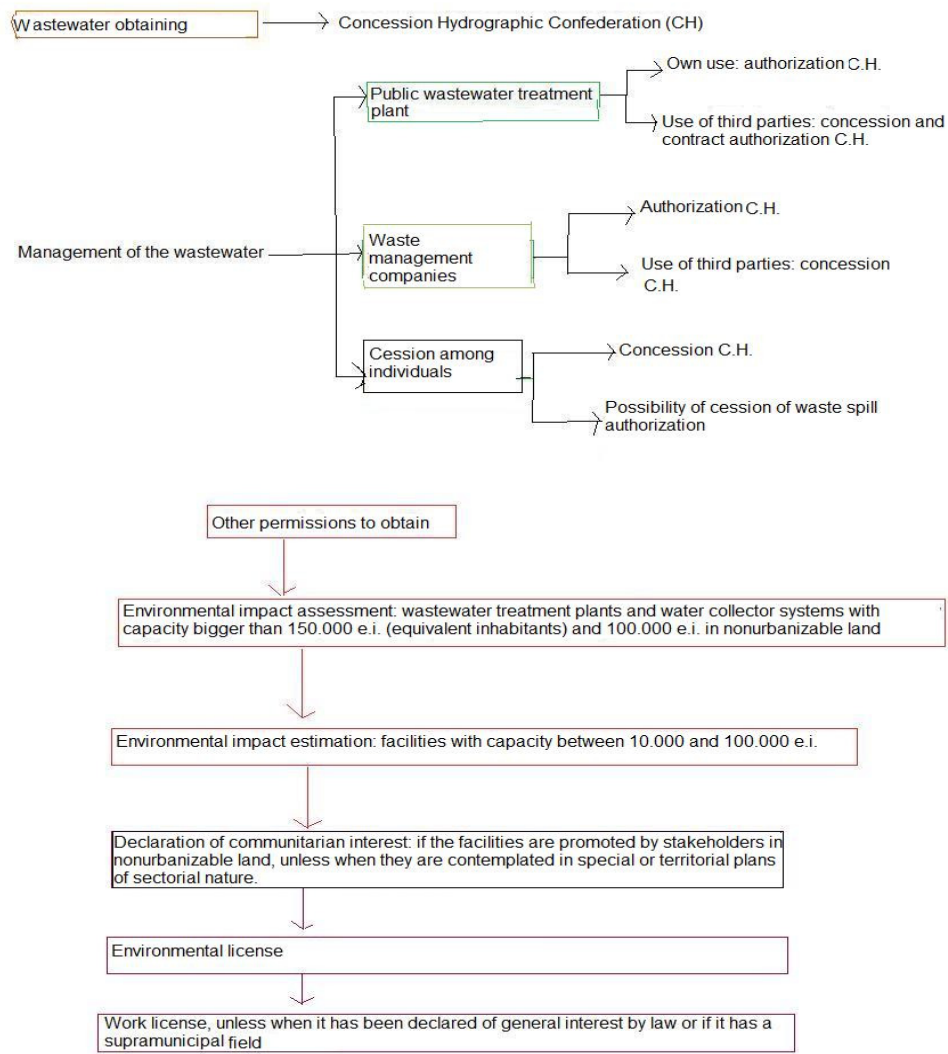

Figure 1: Concessions, authorizations and permissions to request for activities of treatment and water reuse in the different administrations. 
In order to make the planned direct reuse in appropriate conditions is necessary to fulfill some requirements: wastewater availability which sometimes will need additional treatments; studies of economic, social and environmental feasibility; rules that define the quality limits based on the possible uses; management and operation systems of recycled wastewater; and, finally, a wastewater prices policy, that contemplates how and who covers the expenses related to infrastructures, facilities and operation costs associated to reuse.

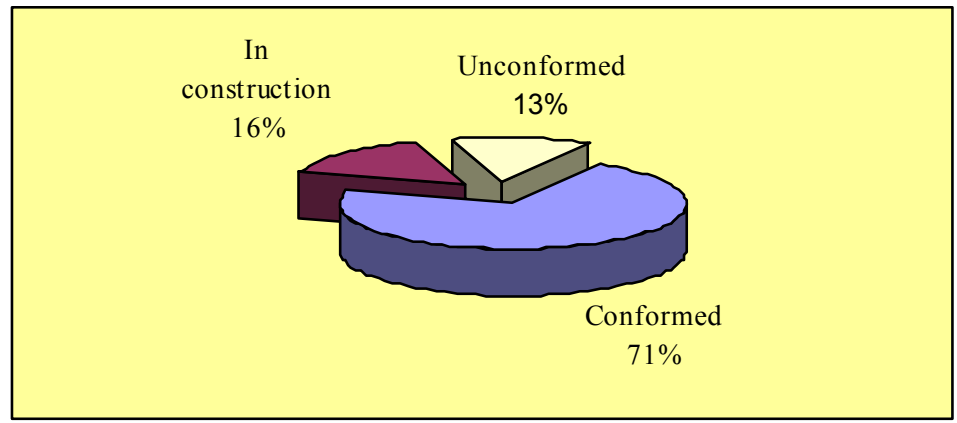

Figure 2: $\quad$ Fulfilment degree of the Directive 91/271/CEE of treatment plants in Spain in 2004.

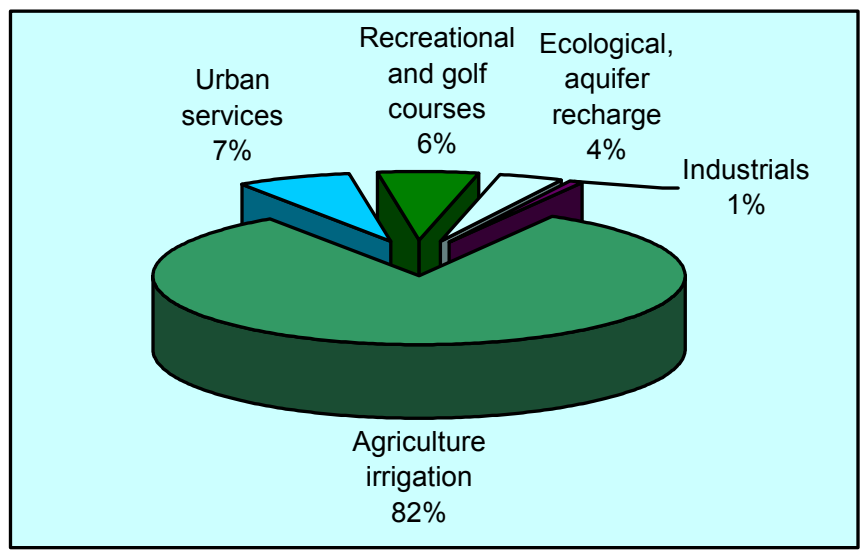

Figure 3: $\quad$ Use percentage of reused wastewaters in Spain in 2002.

Wastewater uses can be incredibly different. It is possible to use them practically for everything, except for human and animal feeding. The use of treated water will depend on its quality. The degree of wastewater treatment(s) will determine the quality of treated water, its cost being variable and increasing as the obtained water has a higher quality. This cost will also depend on the initial characteristics of water received in the plant. 
Wastewater management must be included in an integral planning of water resources, where economic, social and environmental aspects should be considered. Thus, reuse can increase water uses of the already used water, replacing those that do not require high quality water. In addition, the availability of water resources increases because water volumes of better quality could be used for other more demanding uses. Therefore, and agreeing with Hernández [3], who indicates that "the reuse of resources obtained from wastewaters would have to be considered that cannot be waived, as much from the social point of view as environmental and sanitary", since "additionally, optimizing the treatment process using these unconventional resources it would be able to reduce the demand pressure on certain conventional water resources".

However, as a treated water market does not exist, it is difficult to obtain a price for this product; for that reason, it is assumed that the cost per cubic meter must be equal to the maximum sale price, this way guaranteeing to cover the costs. A fundamental question, in this sense, is: Who must or can pay the cost that represents the obtaining of a viable project? Only it can be said that at the moment, in the European Union (EU), there are no concrete subventions which promote water reuse [4]. Now the financing mechanisms can be grouped in two categories: 1) Financing of initial costs, 2) Financing of exploitation costs.

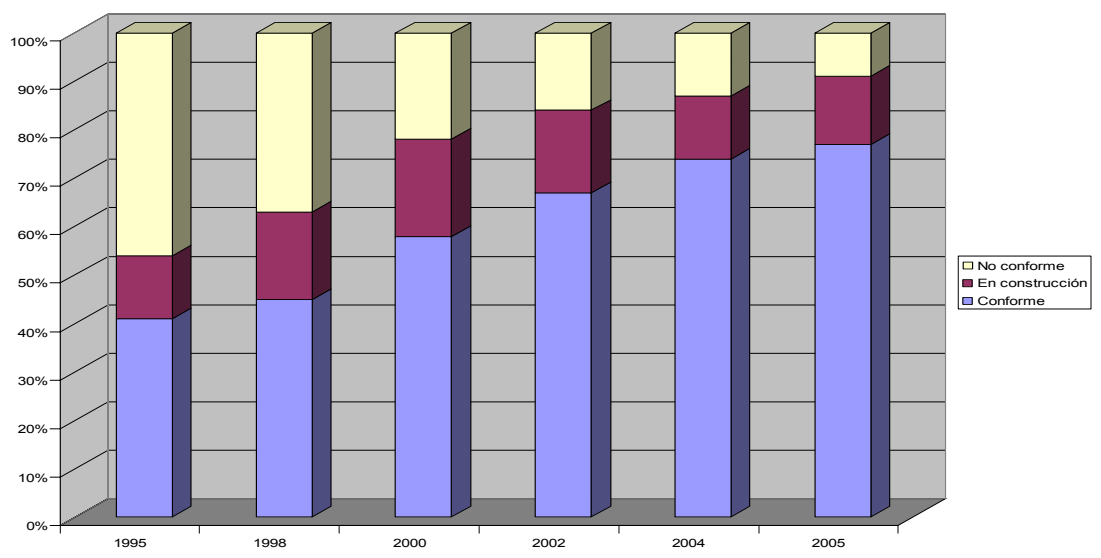

Figure 4: Conformity degree evolution of the polluted load since the publication of the National Plan of Sanitation and Treatment (1995-2005). Source: MIMAM, 2007.

Nowadays, the most extended use of wastewater is agriculture, and the prices paid by this use are symbolic or free. In Spain, the price of water for agricultural use ranges between 0.006 and $0.012 € / \mathrm{m}^{3}$, the supplying one is $0.77 € / \mathrm{m}^{3}$, the desalinated water is around $0.6 € / \mathrm{m}^{3}$ and the price of wastewater treatment (including tertiary treatment) ranges between 0.6 and $0.8 € / \mathrm{m}^{3}$. In view of this situation, it is possible to ask the following question: how the wastewater price could be assumed? The most advisable solution would be the wastewater 
subvention to extend its implementation, otherwise it would be necessary to increase the price of water for agricultural and domestic use. Therefore, in Spain it is essential to establish a price policy that distributes the treatment costs and wastewater management according to the total water consumption. Moreover, incentives must be developed to promote wastewater use in all sectors.

The National Plan of Sanitation and Treatment (1995-2005), at the end of 2005 , presented a conformity degree of $76 \%$, in construction a value of $13 \%$ and $11 \%$ of unconformity. The balance of this plan is very satisfactory, because the conformity degree increased from $41 \%$ in 1995 to $77 \%$ in 2005 , in accordance with the EU rule (figure 4). In addition, the total load obtained in December 2005 was 73.3 million of EI, unconformed being 6.5 million of EI (9\%). On the other hand, in 2007, around 2533 wastewater treatment plants existed in Spain. They treated more than $3,375 \mathrm{hm}^{3} /$ year of wastewater, with a reuse rate of $13.25 \%$ (450 $\mathrm{hm}^{3} /$ year $)$.

The new National Plan of Water Quality: Sanitation and Treatment 2007-2015 have as the main objective, to satisfy not covered and future necessities related to sanitation and wastewater treatment of the Autonomous Regions and the Local Corporations. Thus, the new plan, approved on June 8th of 2007 by the Cabinet Meeting and which count with an estimated cost of 19,007 million euros, tries to complete the fulfilment of the EU exigencies. Consequently, it will contribute to reach in the year 2015, the environmental objectives of the Water Frame Directive and of the program WATER, to face the new investments derived from the sensible zones revision (200 city centres affected by the Resolution of July 2006) and to facilitate the reuse of treated wastewater until reaching 3,000 annual cubic hectometres. Table 1 shows the provisional national summary of total investments, in million of euros, to carry out in the Autonomous Regions. Through this plan, the government will collaborate with the Territorial Administrations on the development of their corresponding actions to guarantee the terms and conditions fulfillment of the requirements derived from the EU directives. The Ministry of Environment will work in the following aspects. The carrying out of the declared actions of general interest for the State that are unresolved, with a budget of 3,046 million euros. Accomplishment of actions, using an amount of $25 \%$ of its cost, to improve the water quality in the "sensitive zones" of our rivers or coasts, all this derived from the declaration made by Spain or Portugal about Sensitive Zones, investing for it 557 million euros. Participation to $50 \%$ with the Autonomous Regions in actions that affect the National Parks and in municipalities with territories of the Network Natura 2000, to assure the water quality in these more demanding environments, with a total amount of 1,200 million euros. Financing, without interest, $50 \%$ of the actions that will be agreed with the Autonomous Regions, recovering the investment in 45 years, through the State Water Societies, with a maximum amount of 1,430 million euros. In short, the MIMAM will participate with 6,233 million euros, of which 3,046 are inherited of the Plan of Sanitation 1995-2005. The objective, with this National Plan of Water Quality, is to make possible the reuse of water, with its consequential offer increased until reaching approximately $3000 \mathrm{hm}^{3} /$ year available in 2015 . 
Table 1: $\quad$ Provisional national summary of total investments, in million of euros, to be carried out by the Autonomous Regions.

\begin{tabular}{llcc}
\hline 1 & $\begin{array}{l}\text { Declared actions of general interest (actions of Hidrographic } \\
\text { Confederations and State Societies are included) }\end{array}$ & $1.114 €$ & $5,7 \%$ \\
2 & $\begin{array}{l}\text { Actions without wastewater treatment plant or with } \\
\text { wastewater treatment plant unconformed }\end{array}$ & $2.903 €$ & $14,8 \%$ \\
3 & Actions due to the new declaration "Sentitive zones" & $4.782 €$ & $24,3 \%$ \\
4 & Actions to cover future necessities & $5.620 €$ & $28,6 \%$ \\
5 & Actions to contribute to reach the objectives of the Frame & $1.938 €$ & $9,9 \%$ \\
6 & Water Directive (Directiva Marco del Agua DMA) & $2.741 €$ & $14,0 \%$ \\
7 & Actions in sanitation (without treatment) & $547 €$ & $2,8 \%$ \\
& Actions to promote I+D+i in sanitation and treatment \\
TOTAL & $19.645 €$ & $100 \%$ \\
\hline
\end{tabular}

Source: MIMAM, 2006.

Until then, the analysis of treated water reuse focused in technical and legal aspects have had an important development and its methodology in general has been well structured. On the contrary, environmental, social and economic aspects are enormously delayed, and methodologic budgets require to be reinforced. It is necessary to indicate the new legal definition of recycled wastewater: treated wastewater that, in their case, have been treated by an additional or complementary treatment allowing to obtain a required quality according to the use to which they are destined (RD 1620/2007, Dec. 7th). It is a term that every day acquires more strength and it is related with the search of the social acceptance of this water, since, from the technical point of view and in wastewater field, treated effluent, treated water and recycled water are synonymous.

It is necessary to emphasize the potential use of recycled wastewater reuse. In the first place, it is used for agriculture (culture lands, grass, ornamental zones, industrial cultures, aquiculture, nursery...); secondly, for aquifer recharge, with the purpose of solving environmental problems of fight against marine intrusion and regeneration of some lost ecosystems by excessive exploitation; thirdly, for environmental and recreational uses (golf courses, forestry, green spaces inaccessible to the public), urban (irrigation of private gardens, street washing) and industrials (textile sector). So, it is required that the regional administrations regulate these questions of using exclusively treated water forcing to any set going project, as well as the already existing ones.

\subsection{Costs of treatment and water reuse in Spain}

In Spain, the average cost of treated water by means of membranes for agricultural irrigation is $0.5 € / \mathrm{m}^{3}$. In the Valencian Region, in 2006, according to data of the Public Water Management Organisation (EPSAR-Entidad Pública de Saneamiento de Aguas), there are 415 wastewater treatment plants (148 of them are in the province of Alicante). In addition, 117 of them have water reuse with a volume of $154 \mathrm{hm}^{3}, 20$ plants have tertiary treatments and $170 \mathrm{hm}^{3}$ of capacity. All treatment plants treat an annual volume of $487 \mathrm{hm}^{3}\left(132 \mathrm{hm}^{3} /\right.$ year in the province of Alicante). The yield of Biochemical Oxygen Demand $\left(\mathrm{BOD}_{5}\right)$ 
elimination is of $92 \%$ in the Valencian Region and of $95 \%$ in the province of Alicante. For the mentioned year, the Valencian Region reused in agriculture about $175 \mathrm{hm}^{3}$, approximately the number that represents half of the total reuse in Spain. In Castellón, the volume of reused water was $16.5 \mathrm{hm}^{3}$, in Valencia $88.5 \mathrm{hm}^{3}$ and $52.6 \mathrm{hm}^{3}$ in Alicante. In the case of Alicante, the annual volume that can be treated is $132 \mathrm{hm}^{3}$, of these only $52.6 \mathrm{hm}^{3}$ were reused. For that reason, $79.4 \mathrm{hm}^{3}(39,84 \%)$ of total treated water obtained in the province was not reused. According to the EPSAR, in 2010, the region will be able to reuse 350 $\mathrm{hm}^{3} /$ year, which means an increase of double.

Which are the costs to treat and to reuse water? It is necessary to begin indicating that the costs of treatment and water reuse are conditioned by the existence of several factors. In the first place, it has to be considered the type of water to treat, since its origin determines the class and level of polluting agents which have to be eliminated and the type of treatment to apply. Secondly, it must be considered the use (different qualities) that water will have, because different processes will be used according to the application required. There is an enormous variability of costs associated to the different treatments. They increase when the number of processes involved increase. Some uses, like those associated to an industrial reuse and those that are destined to aquifer recharges, also have significant price variations. Special attention has been paid to the subject of power costs, since consumption is very unequal (and, therefore, the cost) according to the chosen technique. Thus, it is necessary to consider clearly the correlation between pollution degree of treated water (measured by the quotient between the EI served and the processed cubic meters) and the energy consumption of the plant.

\subsection{Cost examples in the Valencian Region}

In the Valencian Region, according to the collected data, treatment cost has a value of $0.220 € / \mathrm{m}^{3}$, that are distributed as follows: personnel costs, $0.088 € / \mathrm{m}^{3}$ (40\%); energy, $0.042 € / \mathrm{m}^{3}(19 \%)$; wastes, $0.035 € / \mathrm{m}^{3}$ (16\%); maintenance, 0.026 $€ / \mathrm{m}^{3}(12 \%)$; reagents, $0.015 € / \mathrm{m}^{3}(7 \%)$, and under the denomination of "others" (material of laboratory, vehicles, fuel, gardening, etc.) there are expenses of $0.014 € / \mathrm{m}^{3}(6 \%)$. Also, operation costs differ sensitively according to the different treatments used. For secondary treatment, the cost is $0.26 € / \mathrm{m}^{3}$; for tertiary treatment, $0.06 € / \mathrm{m}^{3}$; for advanced treatment, $0.14 € / \mathrm{m}^{3}$. It is assumed that the distribution cost is $0,1 € / \mathrm{m}^{3}$.

In order to determine the price that final users must pay by recycled water consumption, in addition to the price that entails obtaining this resource, it is necessary to consider other additional costs, such as the expenses derived from the use of cooling towers, the update of pipes, etc. On the other hand, it would be beneficial to count with the existence of subventions, financing at low interests or the possibility of reducing the global cost of the system. As a result, it would reduce the price at which recycled water can be offered. In addition, it has to be considered that many companies apply tariffs to recycled water based on a percentage of the drinkable water price. With this measure it is trying to foment 
its use, but the global cost of the reuse project cannot be recovered, nor either include the cost of distribution systems. The price system of recycled water should consider the costs, including the intrinsic value of water as a resource, its environmental effects and the cost of the opportunity that entails its use.

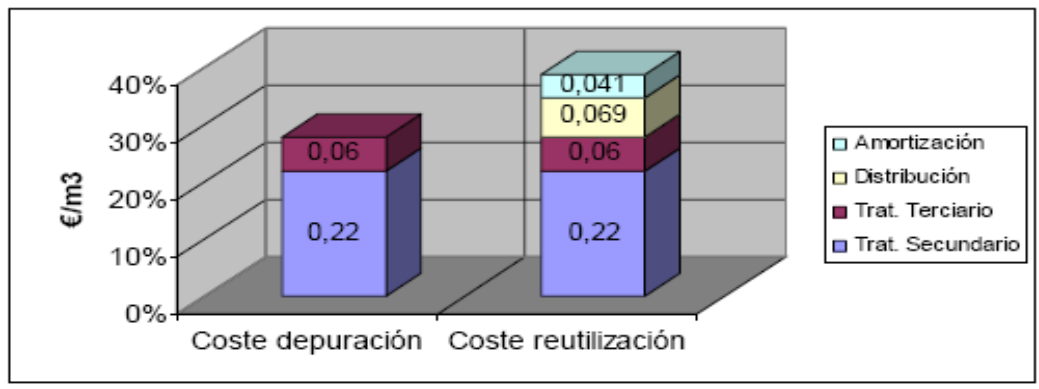

Figure 5: Costs of treated and reused water in the Valencian Region. Source: EPSAR, 2007.

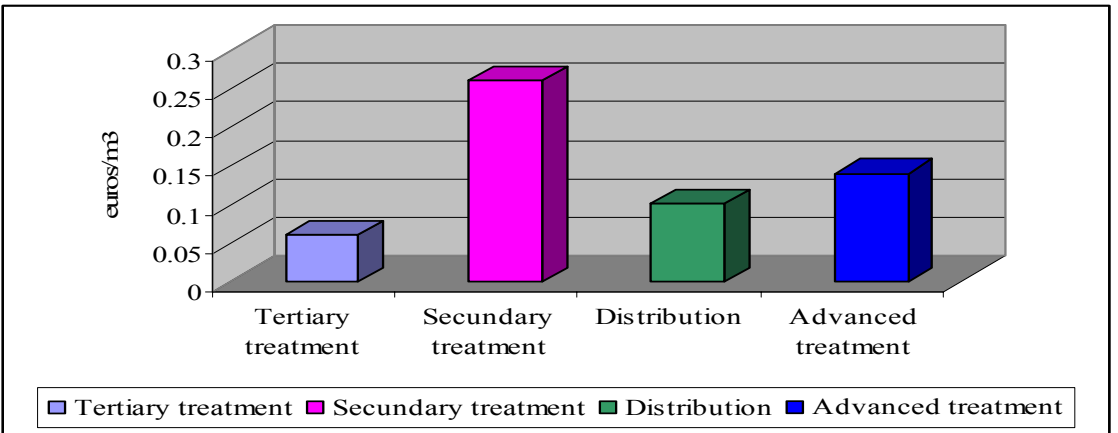

Figure 6: Exploitation costs of recycled water in the Valencian Region. Source: EPSAR, 2007.

In the Valencian Region, the prices of recycled water, including treatment costs, increase to $0.28 € / \mathrm{m}^{3}\left(0.22 € / \mathrm{m}^{3}\right.$ of secondary treatment and $0.06 € / \mathrm{m}^{3}$ of the tertiary treatment). Taking into account the reuse cost, the price of recycled water increases to $0.39 € / \mathrm{m}^{3}\left(0.22 € / \mathrm{m}^{3}\right.$ of secondary treatment, $0.06 € / \mathrm{m}^{3}$ of tertiary treatment, $0.069 € / \mathrm{m}^{3}$ of distribution and $0.041 € / \mathrm{m}^{3}$ of amortization).

\section{Conclusions}

In countries, where there is a lack of water, treated water with acceptable quality levels becomes essential for later reuse. In some zones of Spain, water treatment is being implemented for its massive reuse. In order to obtain this objective, the 
1st National Plan of Sanitation and Wastewater Treatment 1995-2005 has been completed. At the present time, the new National Water Plan: Sanitation and Treatment 2007-2015 is in force, which is expected to reuse more than $3000 \mathrm{hm}^{3}$ of water per year. For that, there is a budget of 19645 million euros, that will be co-financed by the State and Autonomous Regions. In Spain, the average cost of treated water for reuse is $0,39 € / \mathrm{m}^{3}$.

\section{Acknowledgements}

This study was partially financed by the Ministry of Environment with the projects "Water resources generation by means of membrane processes" (NF MBR/NF) CTQ200766780 and "Treatment and wastewater reuse for a sustainable management” (CONSOLIDER) (CSD200644).

\section{References}

[1] LIBRO BLANCO DEL AGUA: Ministerio de Medio Ambiente, Secretaría de Estado de Aguas y Costas, Dirección General de Obras Hidráulicas y Calidad de las Aguas, 2000.

[2] Iglesias, R., Escenarios existentes y propuestas para el avance de la regeneración y reutilización de aguas en España. Jornadas Técnicas: La integración del agua regenerada en la gestión de los recursos, Lloret de Mar (Girona), 2005.

[3] Hernández, F., \& Sala, R., Modelización de costes en los procesos de tratamiento de aguas residuales: un análisis empírico para la Comunidad Valenciana. Universidad de Valencia, 2006.

[4] Hernández, F., De Las Fuentes, L. \& Urkiaga, A., Guía para la realización de estudios de viabilidad en proyectos de reutilización de aguas depuradas. AQUAREC, MIMAM y Ministerio de Fomento, 2006.

[5] López Ortiz, M. \& Melgarejo Moreno, J. Depuración y reutilización de aguas en España: los casos de la Comunidad Valenciana y Murcia”, en GONZÁlEZ VARAS, S. (Coord.), Nuevo Derecho de Aguas. Civitas/Thomson, Navarra, pp. 633-657, 2007.

[6] Mujeriego, R., La reutilización planificada del agua para regadío, XI Congreso Nacional de Regantes, Palma de Mallorca, 2006.

[7] "EPSAR- Entidad Pública de Saneamiento de Aguas" webpage. http://epsar.cop.gva.es/depuradorasv

[8] "MIMAM-Ministry of Environment" webpage. Síntesis del contenido del documento inicial para la evaluación ambiental estratégica". Programa A.G.U.A. Apartado I.S.A: Actuaciones urgentes cuenca mediterránea. www.mma.es

[9] Prats Rico, D. \& Melgarejo Moreno, J, Desalación y reutilización de aguas. Situación en la provincia de Alicante, Fundación COEPA, Alicante, 2006. 